\title{
Three-Dimensional Numerical Analysis of LOX/Kerosene Engine Exhaust Plume Flow Field Characteristics
}

\author{
Hong-hua Cai, Wan-sheng Nie, Xin-lei Yang, Rui Wu, and Ling-yu Su \\ Department of Space Equipment, Equipment Academy, Beijing 101416, China \\ Correspondence should be addressed to Wan-sheng Nie; nws1969@126.com
}

Received 28 November 2016; Accepted 1 August 2017; Published 5 November 2017

Academic Editor: Wen Bao

Copyright (c) 2017 Hong-hua Cai et al. This is an open access article distributed under the Creative Commons Attribution License, which permits unrestricted use, distribution, and reproduction in any medium, provided the original work is properly cited.

\begin{abstract}
Aiming at calculating and studying the flow field characteristics of engine exhaust plume and comparative analyzing the effects of different chemical reaction mechanisms on the engine exhaust plume flow field characteristics, a method considering fully the combustion state influence is put forward, which is applied to exhaust plume flow field calculation of multinozzle engine. On this basis, a three-dimensional numerical analysis of the effects of different chemical reaction mechanisms on LOX/ kerosene engine exhaust plume flow field characteristics was carried out. It is found that multistep chemical reaction can accurately describe the combustion process in the LOX/kerosene engine, the average chamber pressure from the calculation is $4.63 \%$ greater than that of the test, and the average chamber temperature from the calculation is $3.34 \%$ greater than that from the thermodynamic calculation. The exhaust plumes of single nozzle and double nozzle calculated using the global chemical reaction are longer than those using the multistep chemical reaction; the highest temperature and the highest velocity on the plume axis calculated using the former are greater than that using the latter. The important influence of chemical reaction mechanism must be considered in the study of the fixing structure of double nozzle engine on the rocket body.
\end{abstract}

\section{Introduction}

Engine exhaust plume brings a variety of problems for the design and launch of rocket, such as [1] (1) the bottom convective heat transfer problems; (2) the bottom radiation heat transfer problems; (3) the radar signal attenuation problem; and (4) the ground thermal shock problem during the takeoff of the rocket. The study of rocket engine exhaust plume flow field characteristics has the following important application value [2]: (1) the obtaining mature theory and method which can be used to help study tracking large missile $[3,4]$ and (2) studying the attenuation effect of exhaust plume on radio frequency communication signal [5].

Using CFD (Computational Fluid Dynamics) software for exhaust plume flow field calculation has the significant advantages, such as three-dimensional numerical simulation, choosing the turbulence model, obtaining detailed flow field parameters, and so on; it has been widely developed and applied. William and Calhoon's simulation [6] analyzed the rocket exhaust plume flow field using the structured and compressible N-S flow solver software GASP (the General Aerodynamic Simulation Program); the simulation study of Saturn V heavy-lift launch vehicle plume was carried out [7] using the CFD calculation procedures-OVERFLOW. Staged calculation method [2] was used to calculate exhaust plume flow fields: first, get the stagnation temperature and other parameters which can be the inlet boundary condition of second stage using the CEA (Chemical Equilibrium with Applications) from NASA for the zero-dimensional numerical analysis and then calculate exhaust plume flow fields with CFD software FLUENT. Three-dimensional numerical simulation of pure gas-phase single-nozzle [8] and fournozzle [9] exhaust flame flow fields was calculated using the method of large eddy simulation (LES) under the premise of ignoring the chemical reaction influence. FLUENT was used to validate the simplified flow field model of Tomahawk 
TABLe 1: Single-step global chemical reaction.

\begin{tabular}{lcccc}
\hline Reaction & $A$ & $E_{\mathrm{a}}$ & $n_{\text {KERO }}$ & $n_{\mathrm{O} 2}$ \\
\hline $\mathrm{C}_{12} \mathrm{H}_{23}+17.75 \mathrm{O}_{2} \rightarrow 12 \mathrm{CO}_{2}+12 \mathrm{H}_{2} \mathrm{O}$ & $2.587 E 9$ & $1.256 E 8$ & 0.25 & 1.5 \\
\hline
\end{tabular}

cruise missiles BGM-109 [10]. The method of exhaust plume flow field calculation above is conducted without considering the influence of internal combustion state on exhaust plume flow field characteristics. Cai et al. and Feng et al. [11, 12] developed an integrated calculation method of the inner flow field and the plume field of the engine; the effects of combustion chamber combustion model and the nozzle inside surface type on the plume flow field characteristics were studied. The integrated calculation method considered the effect of engine internal combustion state, but it needs a greater number of repeated calculations when calculating the multinozzle engine exhaust plume flow field.

In this paper, a method fully considering the combustion state influence based on the CFD software FLUENT is put forward, which is applied to exhaust plume flow field calculation of multinozzle engine. First of all, the simulation of engine internal flow field is carried out, and the nozzle throat section parameters are as the inlet boundary. Then the calculation of single-nozzle and multinozzle engine exhaust plume flow fields is carried out. Based on the method, numerical analysis of effects of different chemical reaction mechanisms on single-nozzle and double-nozzle LOX/kerosene engine exhaust plume flow field characteristics is carried out.

\section{Mathematical and Physical Model}

2.1. Governing Equations. Multicomponent chemical reaction and conservative three-dimensional N-S equations are used as the flow, the exchange of matter and energy, and the control equation of combustion of the model. The following is the general form of it.

$$
\frac{\partial \vec{U}}{\partial t}+\frac{\partial\left(\vec{F}-\vec{F}_{\mathrm{v}}\right)}{\partial x}+\frac{\partial\left(\vec{G}-\vec{G}_{\mathrm{v}}\right)}{\partial y}+\frac{\partial\left(\vec{H}-\vec{H}_{\mathrm{v}}\right)}{\partial z}=\vec{J},
$$

where $\vec{U}$ is the conservative variable vector; $t$ is the time variable; $\vec{F}, \vec{G}$, and $\vec{H}$ are the convection term vector; $\vec{F}_{\mathrm{v}}$, $\vec{G}_{\mathrm{v}}$, and $\vec{H}_{\mathrm{v}}$ are the viscous term vector; and $\vec{J}$ is the source term vector. The equation above consists quality equation, momentum equation, energy equation, and equation of components in the direction of $x, y$, and $z$, respectively.

2.2. Chemical Reaction Mechanism. There are hundreds of components in kerosene, so it is difficult to describe the actual chemical reaction process accurately. In this paper, single-step global chemical reaction mechanism and multistep chemical reaction mechanism are studied.

The first part is the single-step global chemical reaction, and the actual combustion process of kerosene can be simplified by the alternative fuel $\mathrm{C}_{12} \mathrm{H}_{23}$, by one-step oxidation process; the reaction produces $\mathrm{H}_{2} \mathrm{O}$ and $\mathrm{CO}_{2}$, and the chemical reaction rate $K_{f}$ is calculated by
TABLE 2: Multistep chemical reaction.

\begin{tabular}{lccc}
\hline Reaction & $\mathrm{A}$ & $\mathrm{B}$ & $E / R$ \\
\hline Paraffin global step & & & \\
$\mathrm{C}_{12} \mathrm{H}_{24}+6 \mathrm{O}_{2} \rightarrow 12 \mathrm{CO}+12 \mathrm{H}_{2}$ & $3.888 E 4$ & 1 & $1.220 E 4$ \\
Naphthene global step & & & \\
$\mathrm{C}_{12} \mathrm{H}_{24}+6 \mathrm{O}_{2} \rightarrow 12 \mathrm{CO}+12 \mathrm{H}_{2}$ & $2.132 E 7$ & 1 & $1.965 E 4$ \\
$\mathrm{H}_{2}+\mathrm{O}_{2}=\mathrm{OH}+\mathrm{OH}$ & $1.700 E 13$ & 0 & $2.407 E 4$ \\
$\mathrm{OH}+\mathrm{H}_{2}=\mathrm{H}_{2} \mathrm{O}+\mathrm{H}$ & $2.190 E 13$ & 0 & $2.590 E 3$ \\
$\mathrm{OH}+\mathrm{OH}=\mathrm{O}+\mathrm{H}_{2} \mathrm{O}$ & $6.023 E 12$ & 0 & $5.500 E 2$ \\
$\mathrm{O}+\mathrm{H}_{2}=\mathrm{H}+\mathrm{OH}$ & $1.800 E 10$ & 1.0 & $4.480 E 3$ \\
$\mathrm{H}+\mathrm{O}_{2}=\mathrm{O}+\mathrm{OH}$ & $1.220 E 17$ & -0.9 & $8.369 E 3$ \\
$\mathrm{M}+\mathrm{O}+\mathrm{H}=\mathrm{OH}+\mathrm{M}$ & $1.000 E 16$ & 1 & 0 \\
$\mathrm{M}+\mathrm{O}+\mathrm{O}=\mathrm{O}_{2}+\mathrm{M}$ & $2.550 E 18$ & 0 & $5939 E 4$ \\
$\mathrm{M}+\mathrm{H}+\mathrm{H}=\mathrm{H}_{2}+\mathrm{M}$ & $5.000 E 15$ & -1.0 & 0 \\
$\mathrm{M}+\mathrm{H}+\mathrm{OH}=\mathrm{H}_{2} \mathrm{O}+\mathrm{M}$ & $8.400 E 21$ & 0 & 0 \\
$\mathrm{CO}+\mathrm{OH}=\mathrm{H}+\mathrm{CO}_{2}$ & $4.000 E 12$ & -2.0 & $4.030 E 3$ \\
$\mathrm{CO}+\mathrm{O}_{2}=\mathrm{CO}_{2}+\mathrm{O}$ & $3.000 E 12$ & 0 & $2.500 E 4$ \\
$\mathrm{CO}+\mathrm{O}+\mathrm{M}^{-\mathrm{CO}_{2}+\mathrm{M}}$ & $6.000 E 13$ & 0 & 0 \\
\hline
\end{tabular}

$$
K_{f}=A e^{-E_{\mathrm{a}} / T}[\mathrm{KERO}]^{n_{\mathrm{KERO}}}\left[\mathrm{O}_{2}\right]^{n_{\mathrm{O}_{2}}},
$$

where $T$ is the temperature, the unit is in $\mathrm{K}$; $[\mathrm{KERO}]$ is the molar concentration of kerosene, the unit is in $\mathrm{mol} / \mathrm{cm}^{3}$; and $\left[\mathrm{O}_{2}\right]$ is the molar concentration of oxygen, the unit is in $\mathrm{mol} / \mathrm{cm}^{3}$. The specific values of other parameters are shown in Table 1.

The second part is the multistep chemical reaction mechanism (9 components and 14-step chemical reaction), which is given by $[13,14]$. The chemical reaction rate $K_{f}$ is calculated by

$$
K_{f}=A T^{\mathrm{B}} e^{-E / R T} .
$$

The specific values of the parameters in the formula are shown in Table 2, and as the third carrier, $\mathrm{M}$ does not participate in the chemical reaction.

2.3. Turbulent Combustion Model. Compressible Reynoldsaveraged Navier-Stokes (RANS) equations are adopted in the calculation to describe the turbulent flow of flow field. Realizable $k-\varepsilon$ double equation model is adopted, as it can better simulate large curvature and vortex flow and easier to converge which referred to [15].

The eddy dissipation/finite rate model is adopted in the calculation of single-step global chemical reaction. The eddy dissipation concept model is adopted in the calculation of multistep chemical reaction. In order to effectively avoid the rounding error of big index former factor and activation energy in the rigid mechanism, double precision solver is 


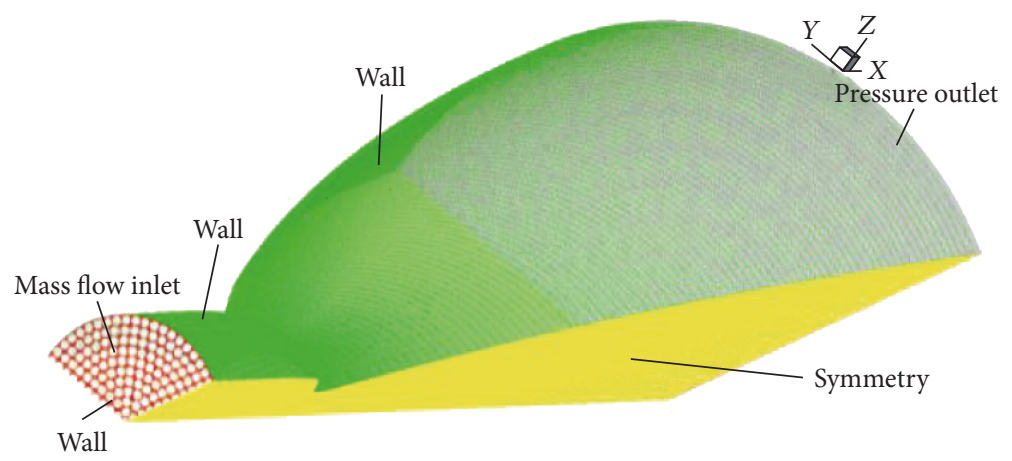

FIgURE 1: Mesh and boundaries of engine internal flow field.

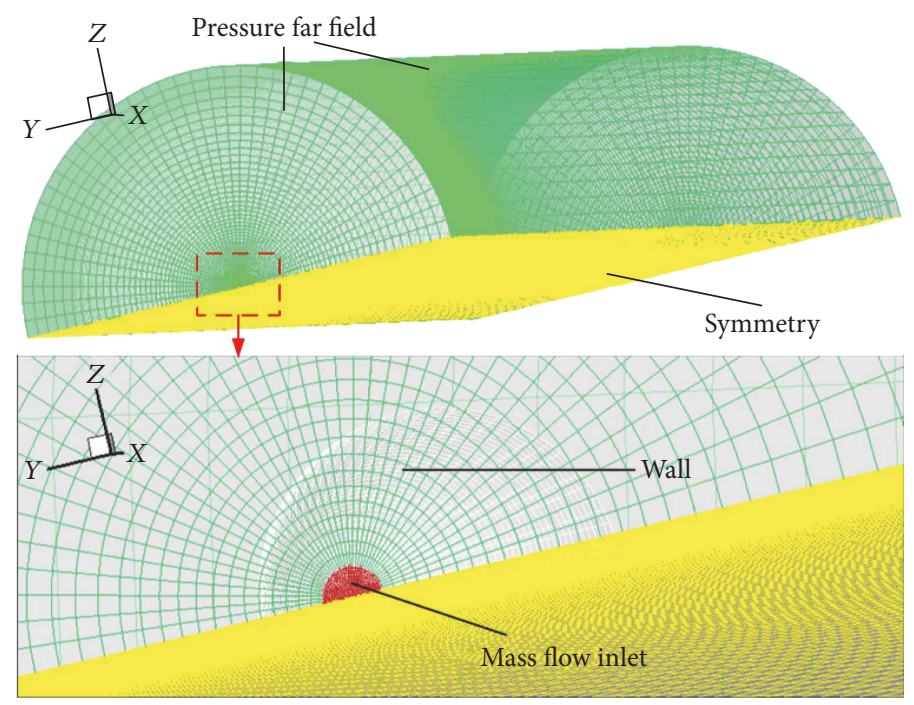

FIGURE 2: Mesh and boundaries of plume flow field of single-nozzle engine.

adopted in the calculation, and the complete multicomponent diffusion and thermal diffusion are considered.

2.4. Disperse and Solution of the Equation. The equations are dispersed in terms of finite volume method, and two order upwind schemes are adopted. Solver based on the pressure is adopted, and the algorithm is PISO (the pressure implicit with splitting of operators) algorithm.

2.5. Grid and Boundary Conditions. Grid generation software is used to deal with the three-dimensional calculation area of the engine internal flow field, the flow field of the singlenozzle engine and the double-nozzle engine; grids and boundary conditions are shown in Figures 1, 2, and 3. In order to save computing resources, according to the symmetry of the engine structure and the calculation area, the internal flow field of the engine is calculated with $1 / 3$ symmetry, and the single-nozzle and double-nozzle exhaust plume flow fields are calculated with $1 / 2$ symmetry. Engine structure is shown in [16], the distance between the two nozzle axes is $1.5 \mathrm{~m}$, and the installation angle is $6^{\circ}$. Calculation areas of single-nozzle and double-nozzle exhaust plumes are the length $130 \mathrm{~m}$ and the radius $15 \mathrm{~m}$ and the length $150 \mathrm{~m}$ and the radius $15 \mathrm{~m}$, respectively.
Boundary conditions of the engine internal flow field are defined as follows: the mass flow inlet boundary is $1.178 \mathrm{~kg} / \mathrm{s}$ and the mixing ratio of oxygen/kerosene is 2.4 ; the engine wall boundary is no-slip wall (refer to the LOX/kerosene engine cooling system design requirements provided by [17]), and the engine cooling process is simplified into a wall temperature of $800 \mathrm{~K}$; and the pressure outlet boundary is of $300 \mathrm{~K}$ and $101,325 \mathrm{~Pa}$. Boundary conditions of the exhaust plume are defined as follows: the mass flow inlet boundary is determined by the engine internal flow field calculation results; the pressure far field boundary is of $300 \mathrm{~K}$ and $101,325 \mathrm{~Pa}$; and the wall boundary is no-slip wall.

\section{Calculation Results and Analysis of the Internal Flow Field of the Engine}

First, grid independence verification is carried out to eliminate the influence of grid quality on the calculation results. 800 thousand, 1.6 million, and 2.4 million grids were used to calculate the international liquid oxygen/kerosene engine combustion flow; the results from the 800 thousand grids are significantly different from that from the 1.6 million grids and the 2.4 million grids and ultimately determine the 1.6 million grids because of the large computing resources 


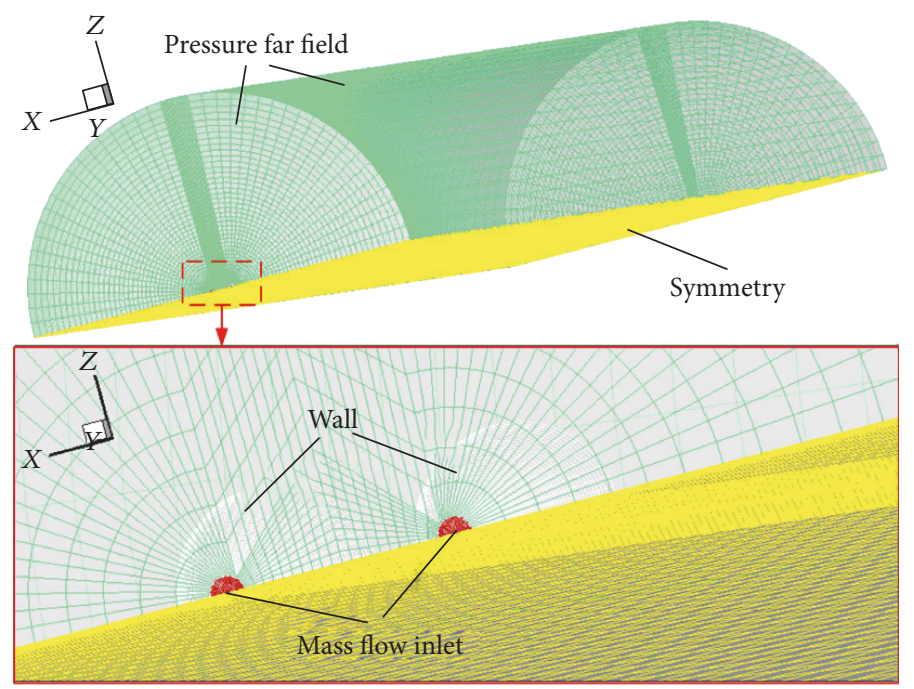

Figure 3: Mesh and boundaries of plume flow field of double-nozzle engine.

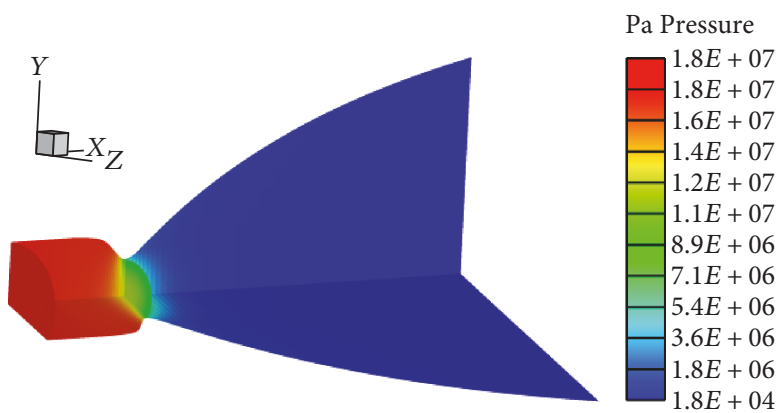

(a) Pressure

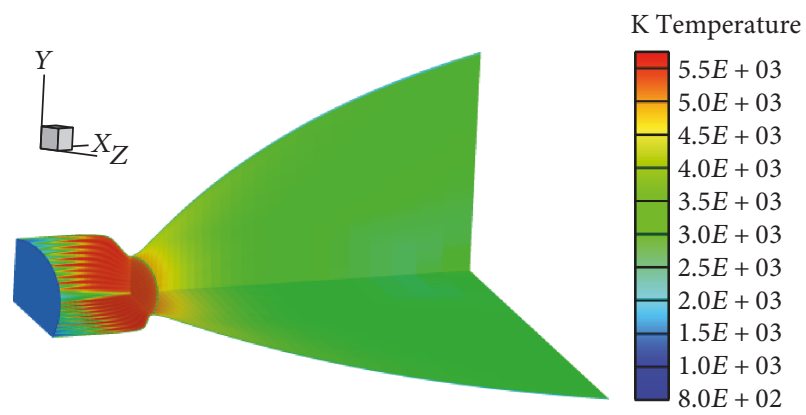

(b) Temperature

FIgURE 4: Flow fields in the engine using the single-step global chemical reaction.

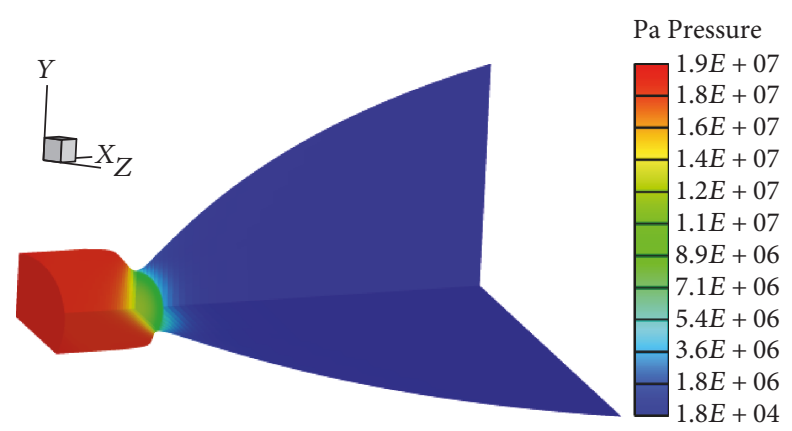

(a) Pressure

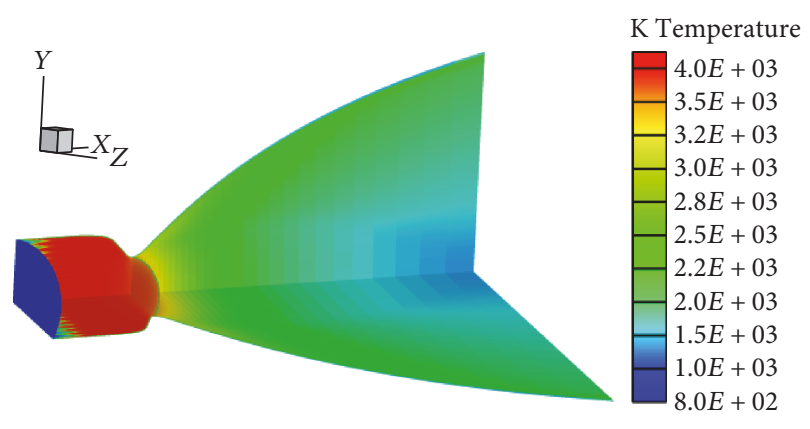

(b) Temperature

FIgURE 5: Flow fields in the engine using the multistep chemical reaction.

of the 2.4 million grids. Internal flow field pressure and temperature distributions obtained using the 1.6 million grids by the single-step global chemical reaction are shown in Figures 4(a) and 4(b); the average pressure of combustion chamber is $17.82 \mathrm{MPa}$, which is $0.68 \%$ greater than 17.7 $\mathrm{MPa}$ obtained by model engine test, and the result is relatively accurate. The average temperature of combustion chamber is $5782 \mathrm{~K}$, which is $51.71 \%$ greater than $3811.17 \mathrm{~K}$ calculated by the thermodynamic calculation of the model engine combustion chamber; this is the result due to ignoring the middle of multistep endothermic reaction process when the single-step global chemical reaction is adopted.

Internal flow field pressure and temperature distributions obtained by the multistep are shown in Figures 5(a) and $5(\mathrm{~b})$. The average pressure of combustion chamber is 18.52 $\mathrm{MPa}$, which is $4.63 \%$ greater than $17.7 \mathrm{MPa}$ obtained 

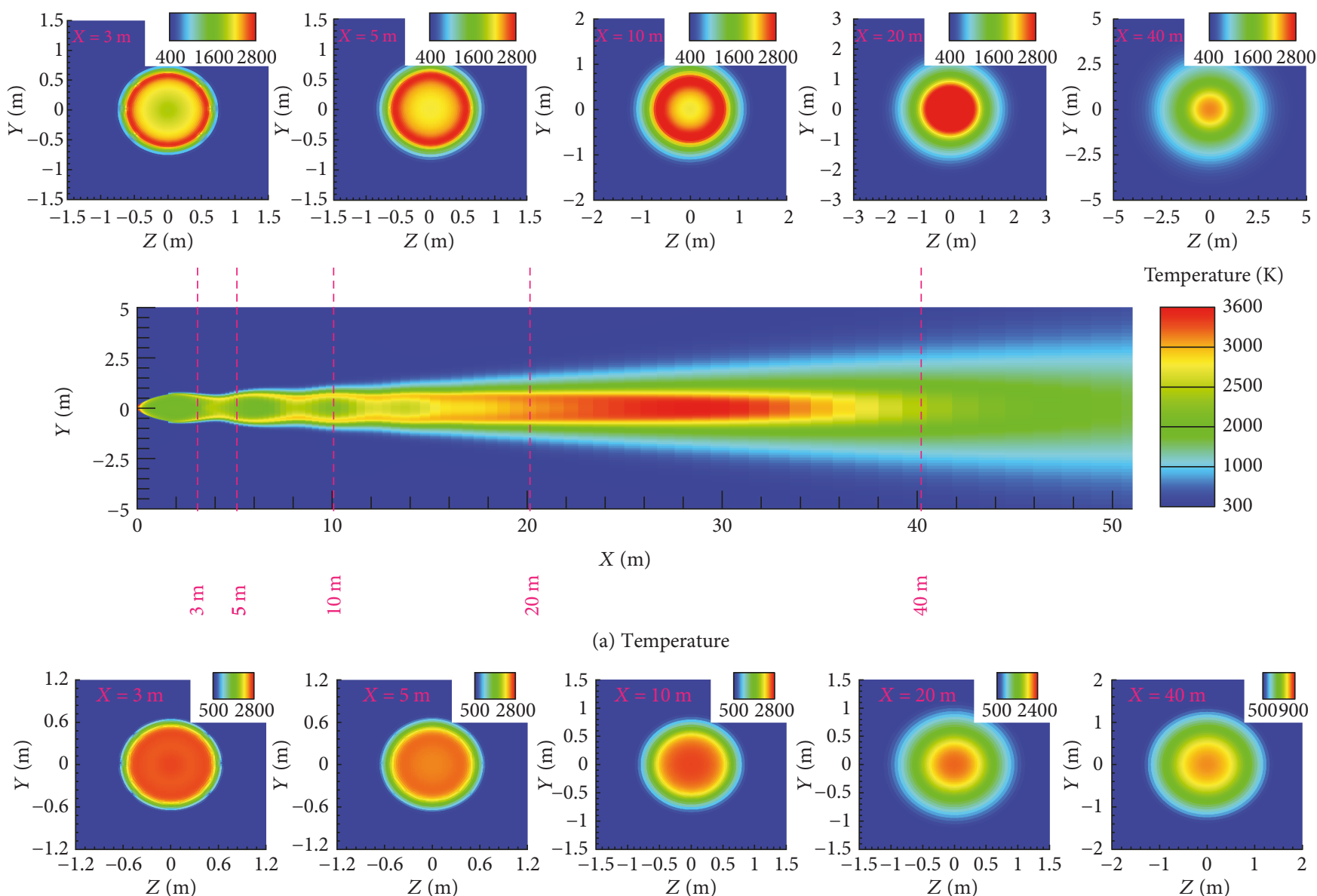

Temperature (K)

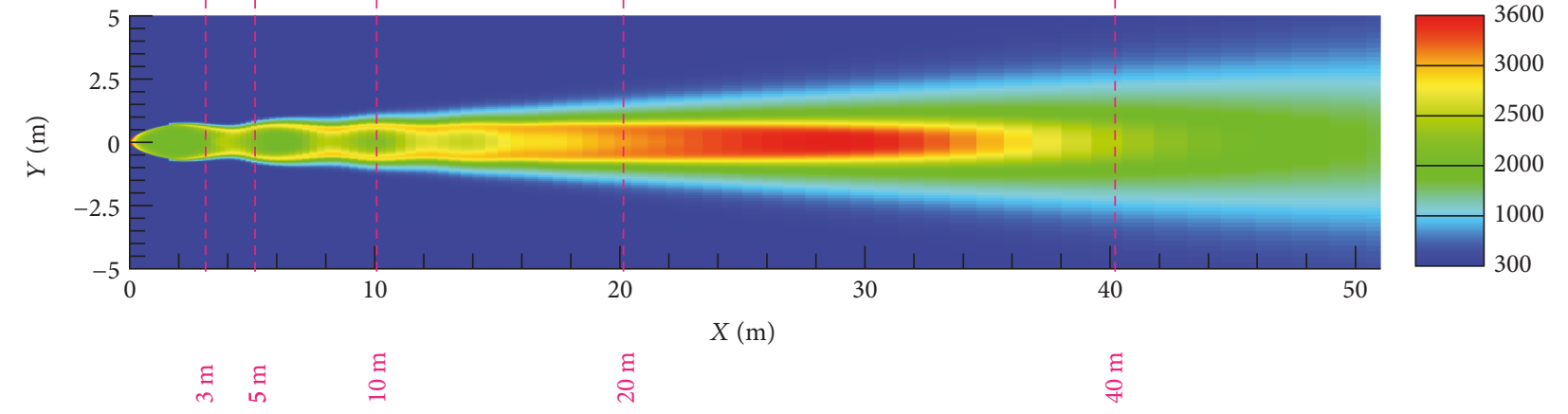

(a) Temperature
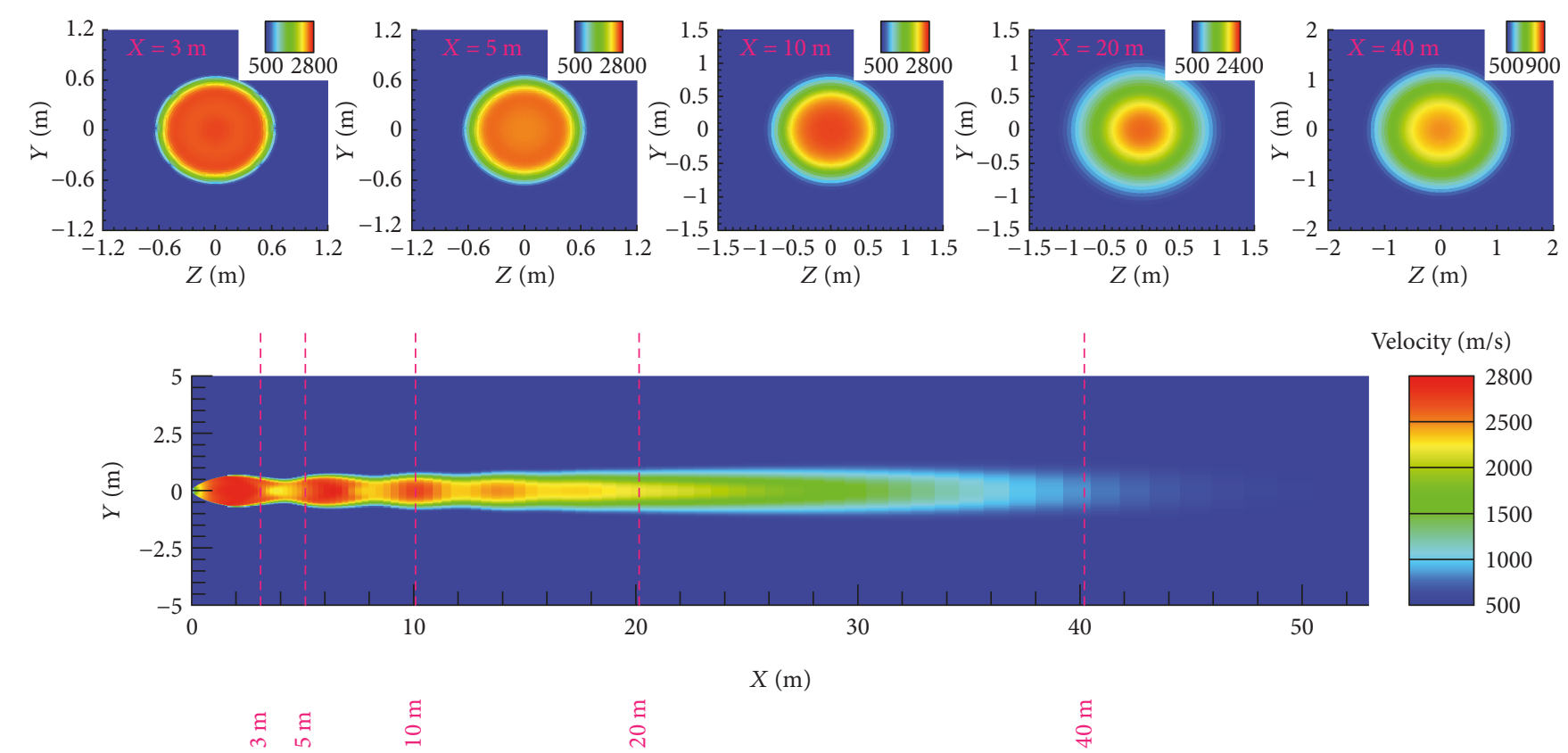

(b) Velocity

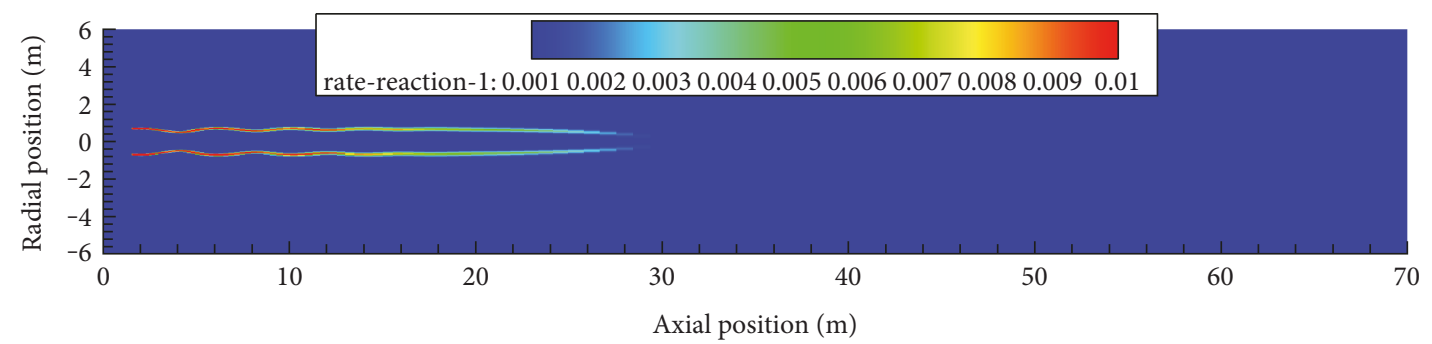

(c) Reaction rate

Figure 6: Plume flow fields of the single-nozzle engine (single step). 

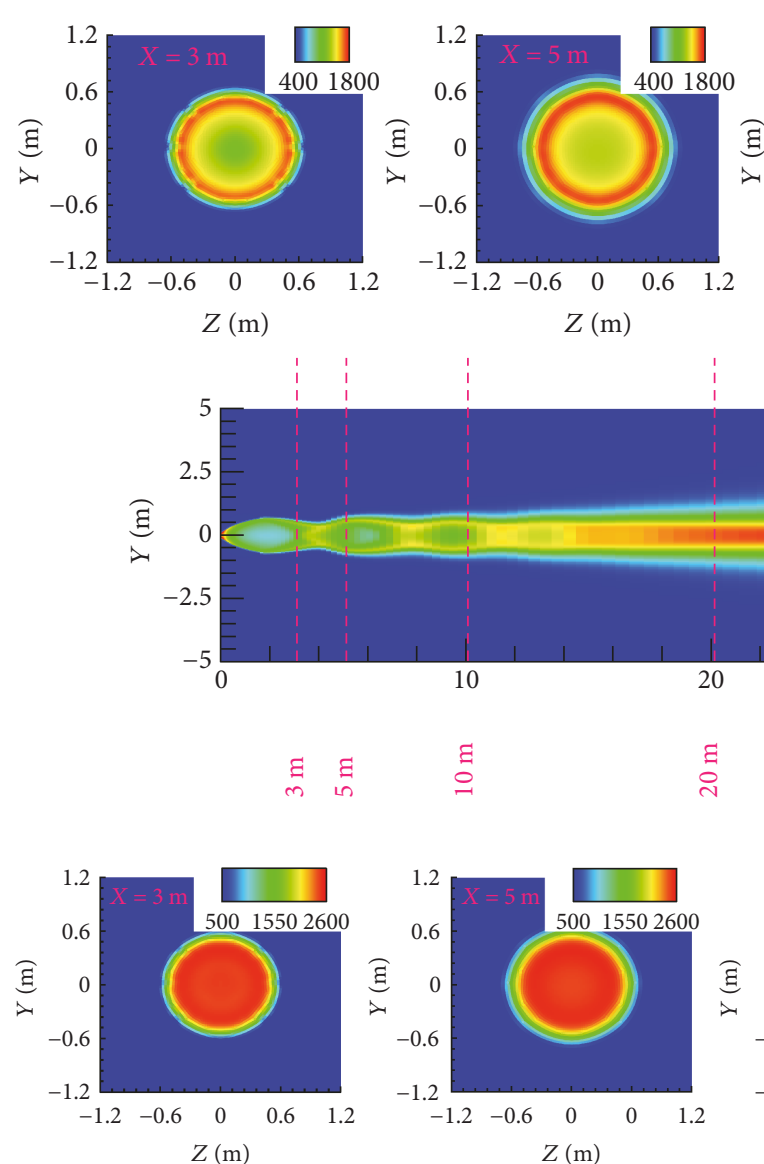

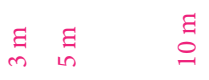
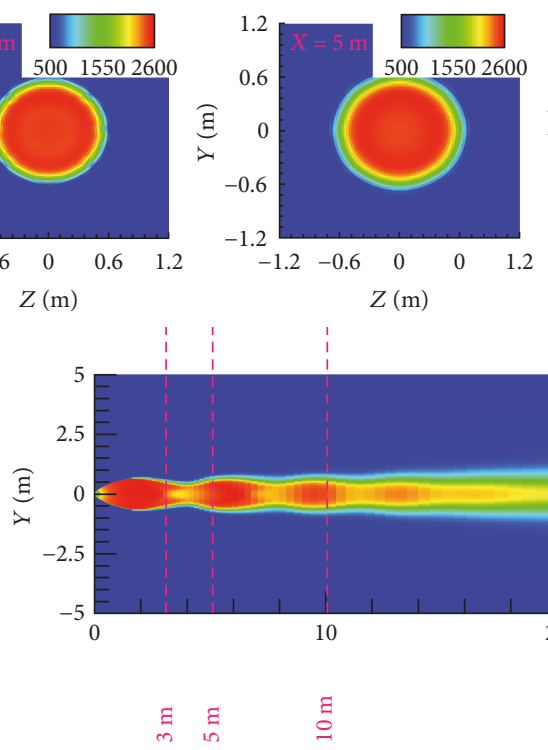

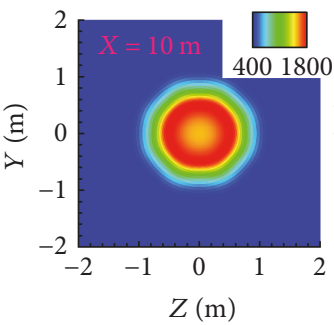

$Z(\mathrm{~m})$

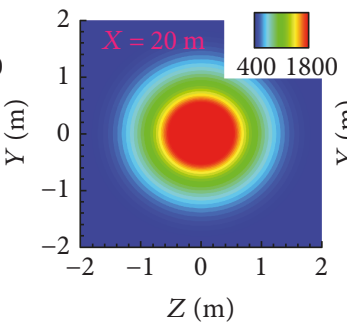

$Z(\mathrm{~m})$

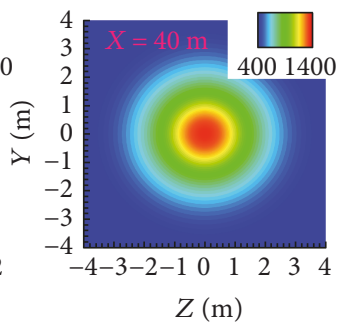

Temperature (K)

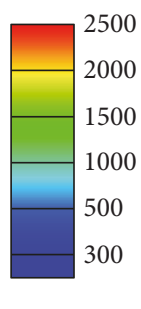

$X(\mathrm{~m})$

ำ
몬

(a) Temperature
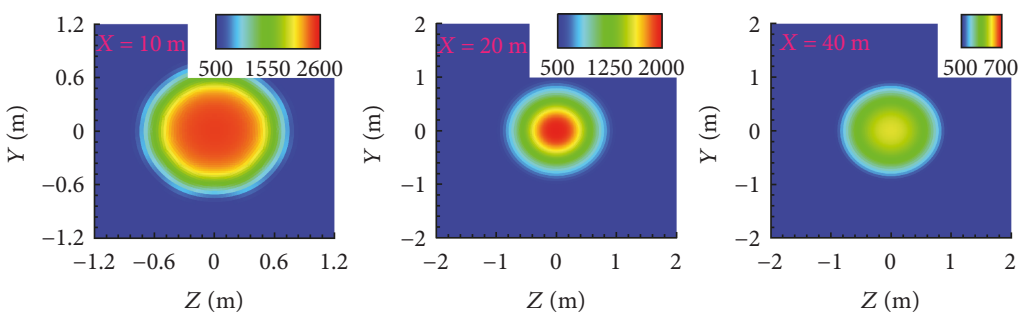

Velocity $(\mathrm{m} / \mathrm{s})$

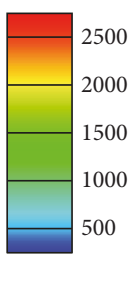

$X(\mathrm{~m})$

(b) Velocity

Figure 7: Continued. 

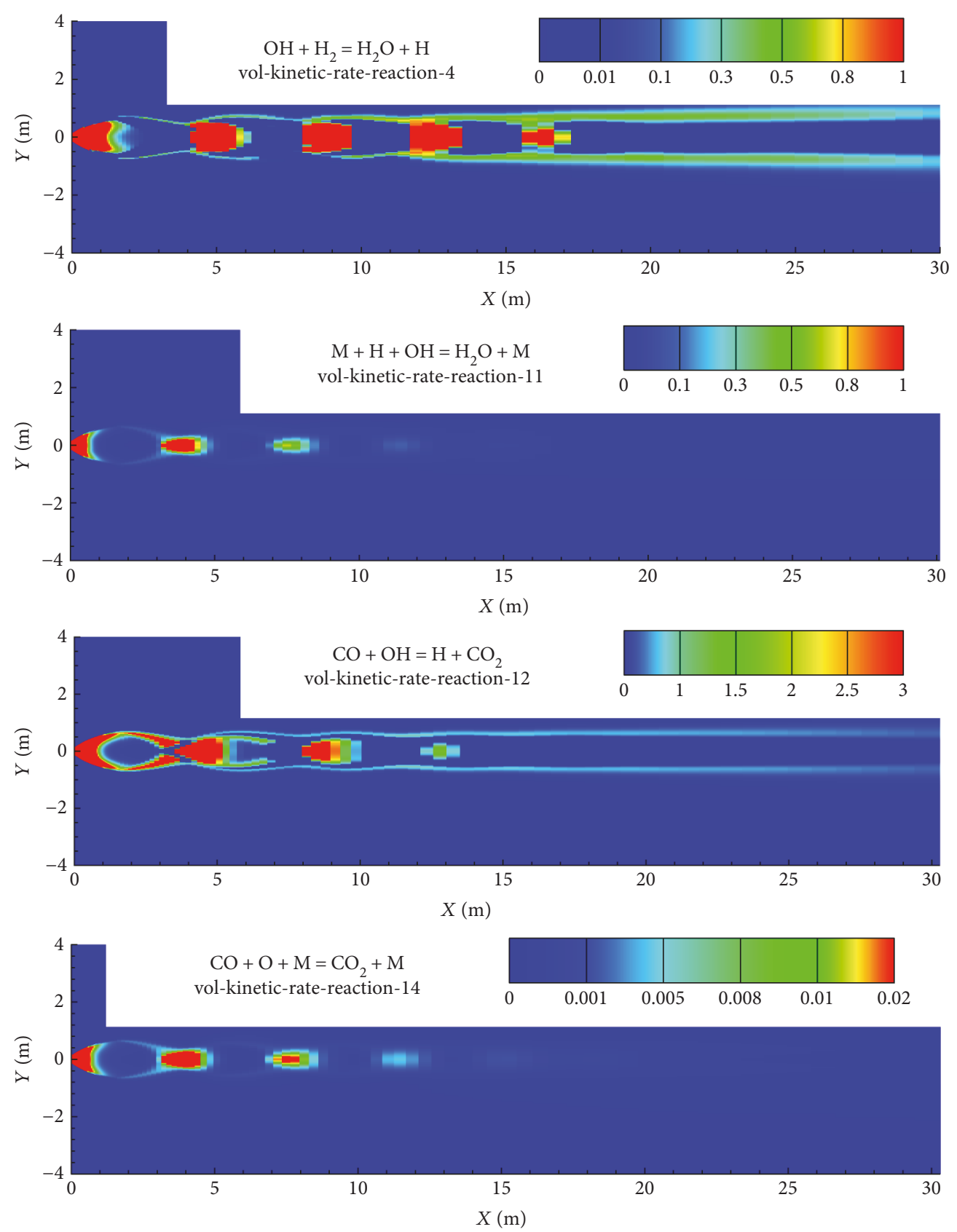

(c) Reaction rate

FIgUre 7: Plume flow fields of the single-nozzle engine (multistep).

by model engine test, and the average temperature of combustion chamber is $3938.53 \mathrm{~K}$, which is $3.34 \%$ greater than $3811.17 \mathrm{~K}$ calculated by the thermodynamic calculation of the model engine combustion chamber, so the result of internal flow field pressure and temperature are relatively accurate.

\section{Calculation Results and Analysis of the Engine Exhaust Plume Flow Field}

4.1. Single-Nozzle Engine Exhaust Plume Flow Field. First, grid independence verification is carried out using 300 thousand, 650 thousand, and 960 thousand grids, and 650 thousand grids is used in considering the accuracy and the cost. The parameter distribution of internal flow field calculated by the single-step chemical reaction is used as the inlet boundary condition, and the plume afterburning reaction is also described using the single-step global chemical reaction. The distributions of temperature, velocity, and reaction rate in the exhaust plume flow field on the different distance cross sections of the axial line and the symmetrical plane are shown in Figures 6(a), 6(b), and 6(c). Exhaust plume gas is ejected from the nozzle into the air of the environment in the infinite region; the air medium is sucked by the plume because of the 


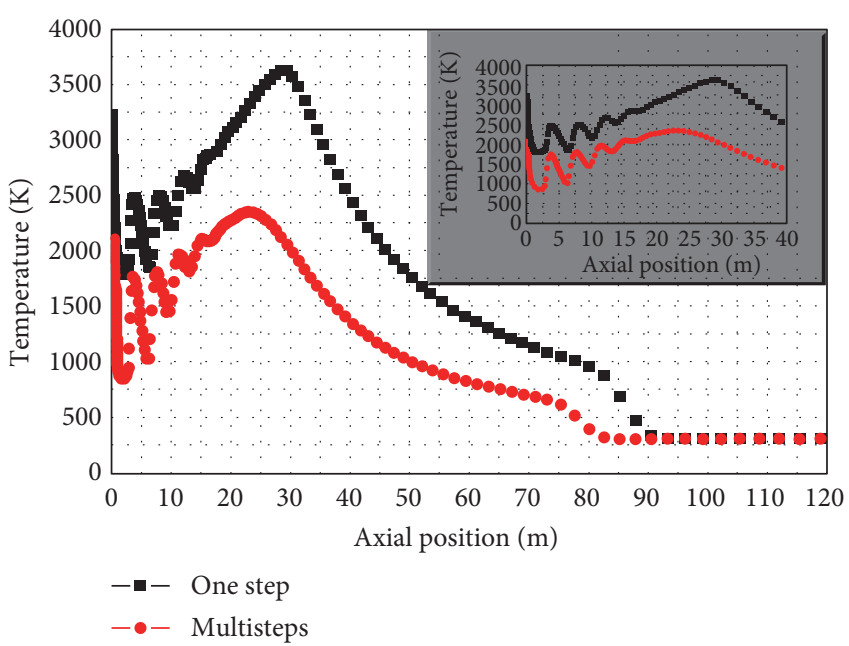

(a) Temperature

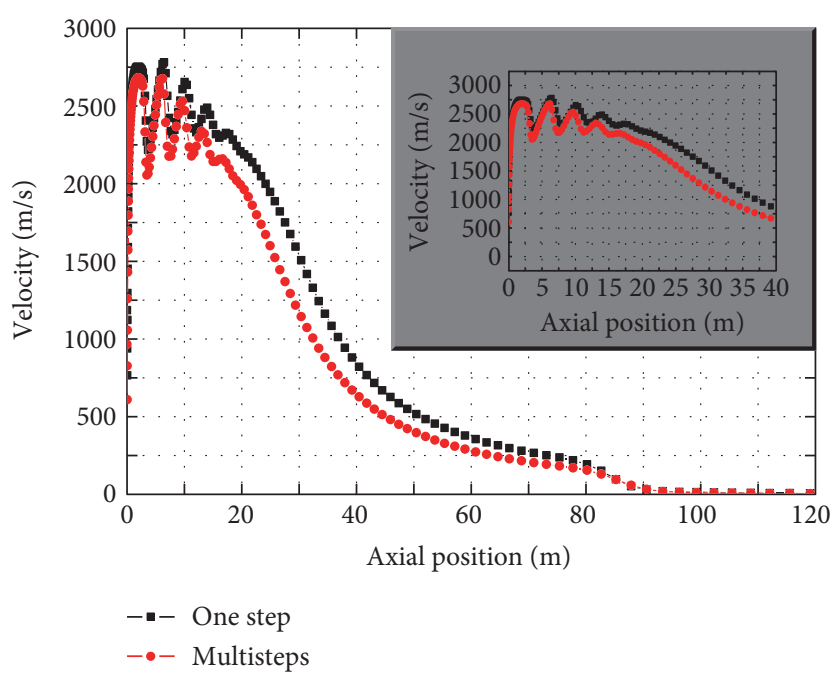

(b) Velocity

Figure 8: Parameters on the plume axis of the single-nozzle engine.

viscous effect, and the momentum and energy conversion exchange between the exhaust plume and the air medium is conducted. As a result, the range of the exhaust plume expands and the velocity and the temperature of the exhaust plume both decrease continuously. Along the radial direction, the plume temperature first increases and then decreases with the ambient temperature; the plume velocity decreases to the environment speed gradually. The first reason is the momentum conversion of the exhaust plume gas and the ambient air mixing, and the exhaust plume gas velocity decreases while the temperature increases; the second main reason is a lot of energy release because of the occurrence of afterburning reaction when the plume and air is mixing, and the mixing area is the main region of afterburning reaction, which causes the temperature rise sharply.

The parameter distribution of internal flow field calculated by multistep chemical reaction is used as the inlet boundary condition, and the plume afterburning reaction is also described by multistep chemical reaction; the distributions of temperature, velocity, and reaction rate in the exhaust plume flow field on the different distance cross sections of the axial line and the symmetrical plane are shown in Figures 7(a) and 7(b). The plume flow field structure is the same with that calculated with the one-step chemical reaction model, but the overall velocity and temperature of the plume reduce significantly; this is because the singlestep chemical reaction model ignores a lot of endothermic reaction process, which leads to the temperature rise sharply. The chemical reaction rate in the exhaust plume flow field is shown in Figure 7(c), all intermediate chemical reactions occur in the core area of the whole plume, and the distribution is like the continuous shock wave; this is the important difference between multistep chemical reaction model and single step chemical reaction model to describe afterburning chemical reaction.

The parameter distribution in the single-nozzle engine obtained by different chemical reaction mechanisms is shown in Figure 8; similar plume flow field structure and the same number of shock waves can be obtained by methods of single-step chemical reaction and multistep chemical reaction, but the length of exhaust plume of the former is $8 \mathrm{~m}$ longer than that of the latter (the judgment standard is the temperature on the plume axis decreases to the ambient temperature or the velocity on the plume axis decreases to the environment velocity), the peak temperature and the peak velocity were $1269.47 \mathrm{~K}$ ( $54.02 \%$ of the latter), and $105.94 \mathrm{~m} / \mathrm{s}$ (3.96\% of the latter) greater than that of the latter. The reasons are as follows: first, a lot of endothermic reaction processes are ignored when adopting the singlestep chemical reaction; thus, the temperature and velocity obtained are higher. Second, exhaust plume afterburning reaction occurs in different regions when different chemical reaction mechanisms are adopted; thus, the exhaust plume flow field temperature and velocity calculated by the former are higher than that of the latter, and the exhaust plume flow field structure also change.

4.2. Double-Nozzle Engine Exhaust Plume Flow Field. First, grid independence verification is carried out using 470 thousand, 750 thousand, and 1.4 million thousand grids, and 750 thousand grids is used in considering the accuracy and the cost. The parameter distribution of internal flow field calculated by single-step chemical reaction is used as the inlet boundary condition, and the plume afterburning reaction is also described by single-step global chemical reaction; the distributions of temperature, velocity, and reaction rate in the exhaust plume flow field on the different distance cross sections of the axial line and the symmetrical plane are shown in Figures 9(a), 9(b), and 9(c). At first, each of the two engine exhaust plumes maintains an independent shock structure, and then, with the increase of the axial distance, the continuous mixing of the exhaust plume and the ambient air leads to the continuous expansion of the exhaust plume; at last, the two exhaust plumes melt into a plume as a whole. The afterburning reaction is the most obvious both in the interface 

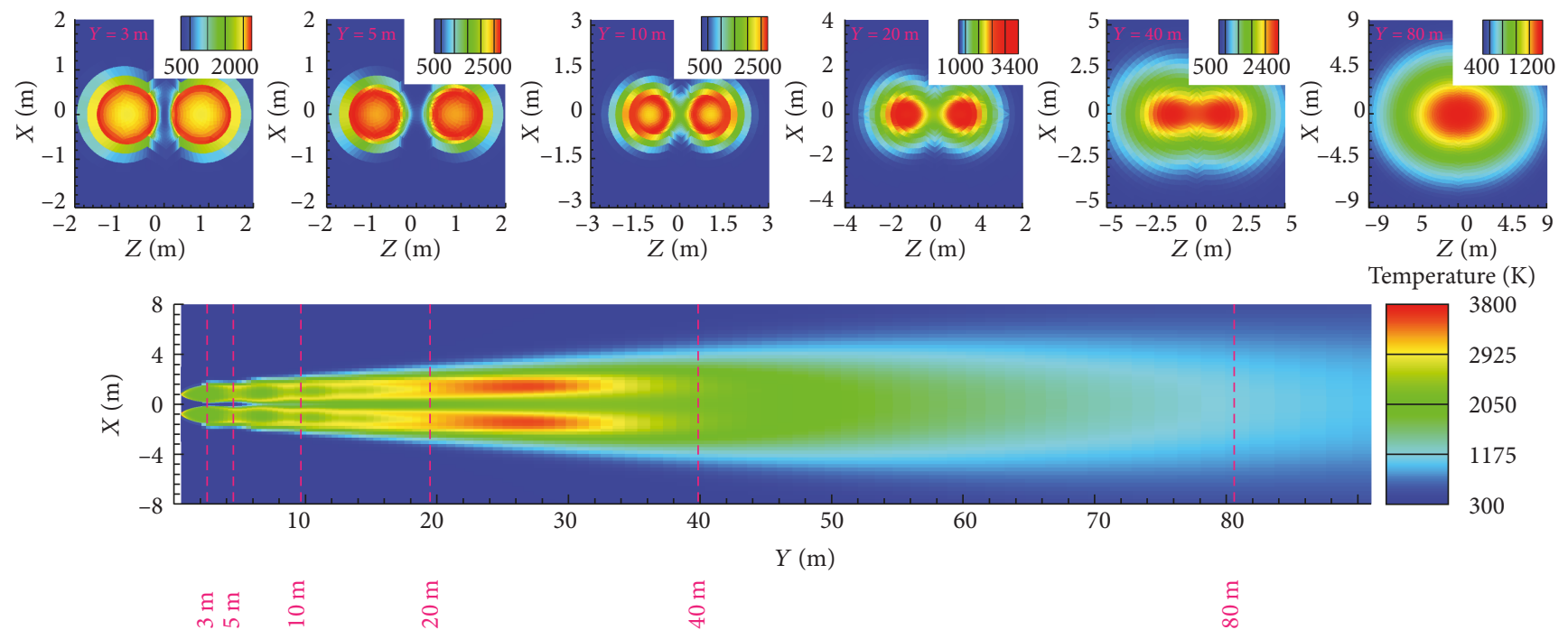

(a) Temperature
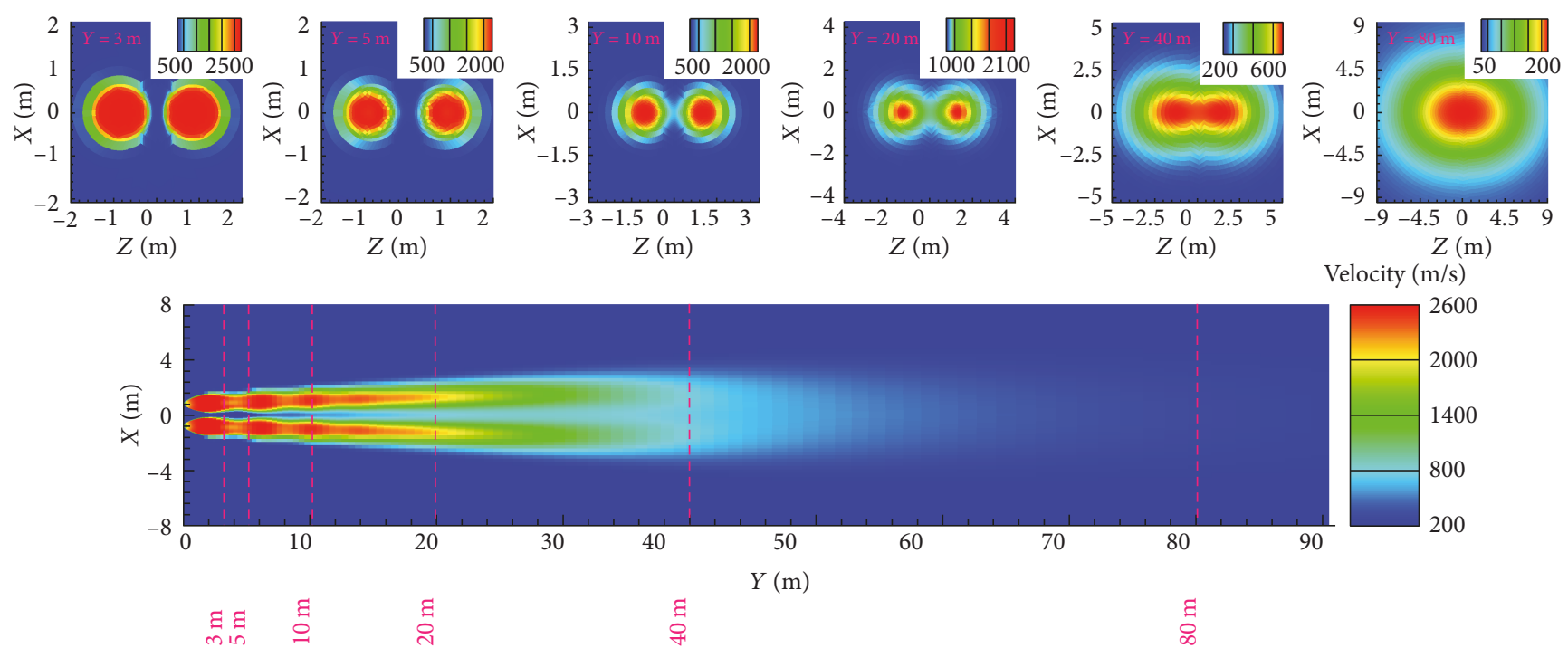

(b) Velocity

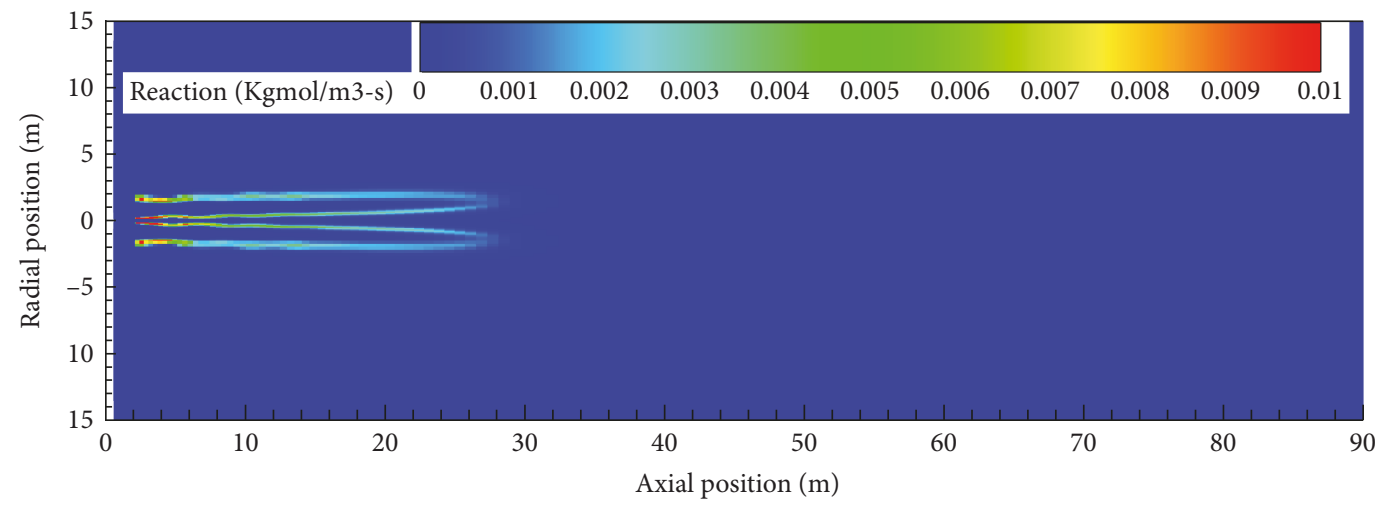

(c) Reaction rate

Figure 9: Plume flow fields of the double-nozzle engine (single step).

between exhaust plume gas and ambient air and also the intersection of two nozzle plume interactions.

The parameter distribution of internal flow field calculated by multistep chemical reaction is used as the inlet boundary condition, and the plume afterburning reaction is also described by multistep chemical reaction. The distributions of temperature, velocity, and reaction rate in the exhaust plume flow field on the different distance cross 

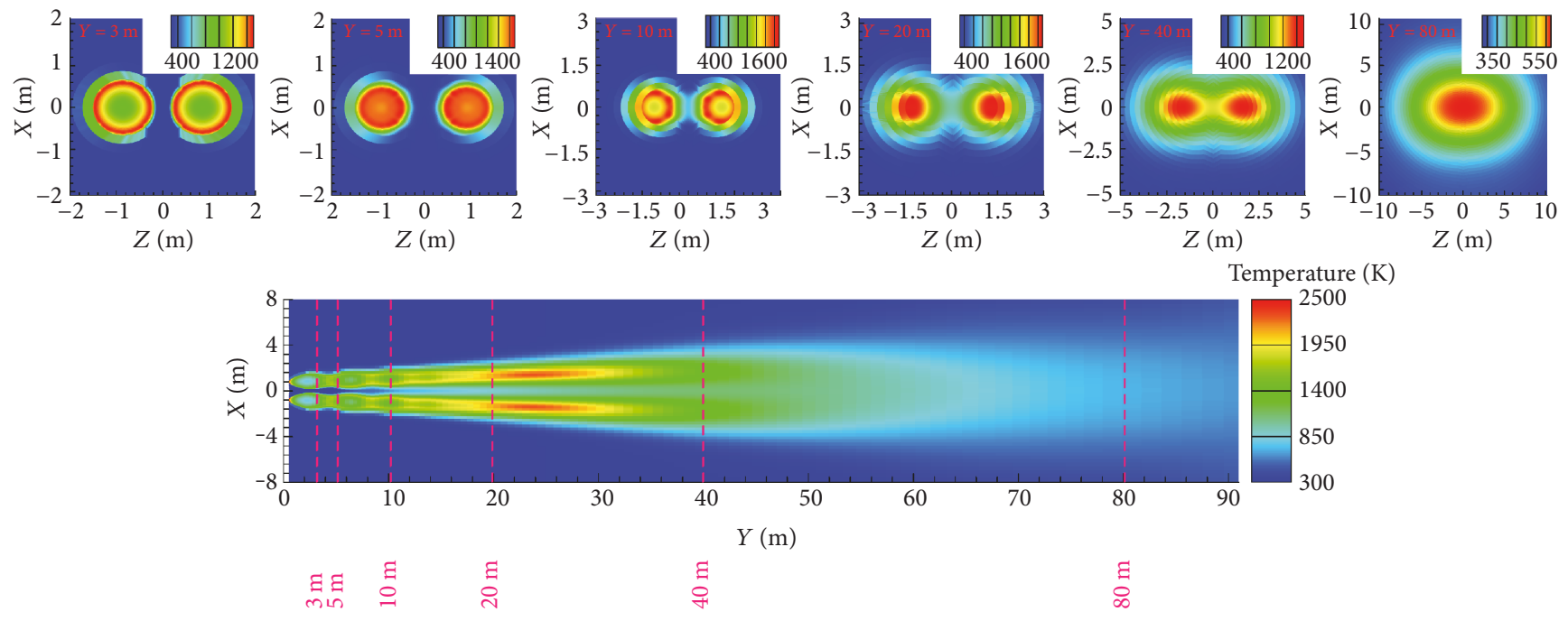

(a) Temperature
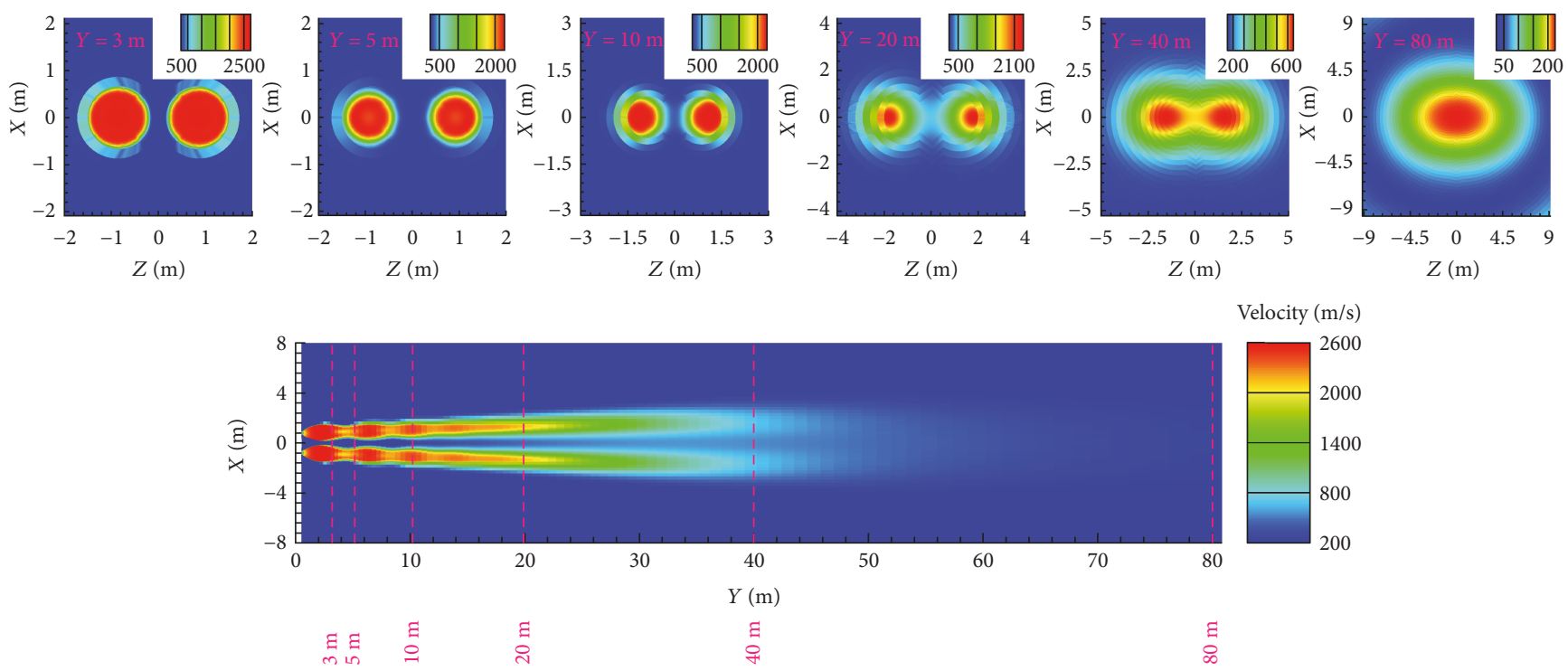

(b) Velocity

Figure 10: Continued. 

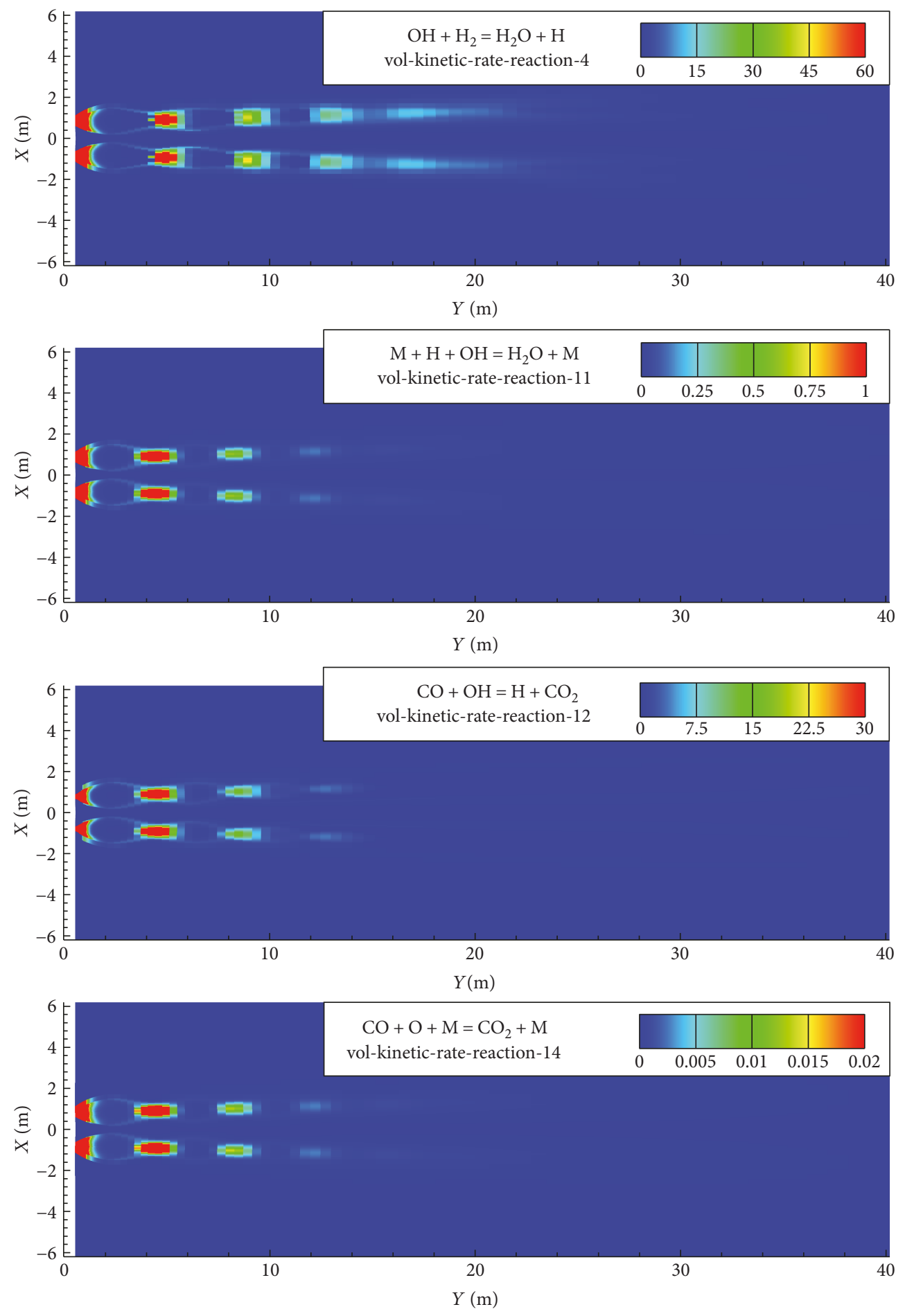

(c) Reaction rate

Figure 10: Plume flow fields of the double-nozzle engine (multistep).

sections of the axial line and the symmetrical plane are shown in Figures 10(a) and 10(b). The exhaust plume flow field structure obtained is similar to that obtained by single-step global chemical reaction; however, as the temperature and the velocity of the exhaust plume gas calculated by the multistep chemical reaction are relatively low, the range of the exhaust plume increases slowly with the increase of axial distance, the interaction between the two exhaust plumes is relatively weak, and the calculation results fully reflect the effect of two engine mounting angles on avoiding the interaction between double engine exhaust plume. The chemical reaction rate in the exhaust plume flow field is shown in Figure $10(\mathrm{c})$, all intermediate chemical reactions occur in the core area of the whole plume, and it is different from 


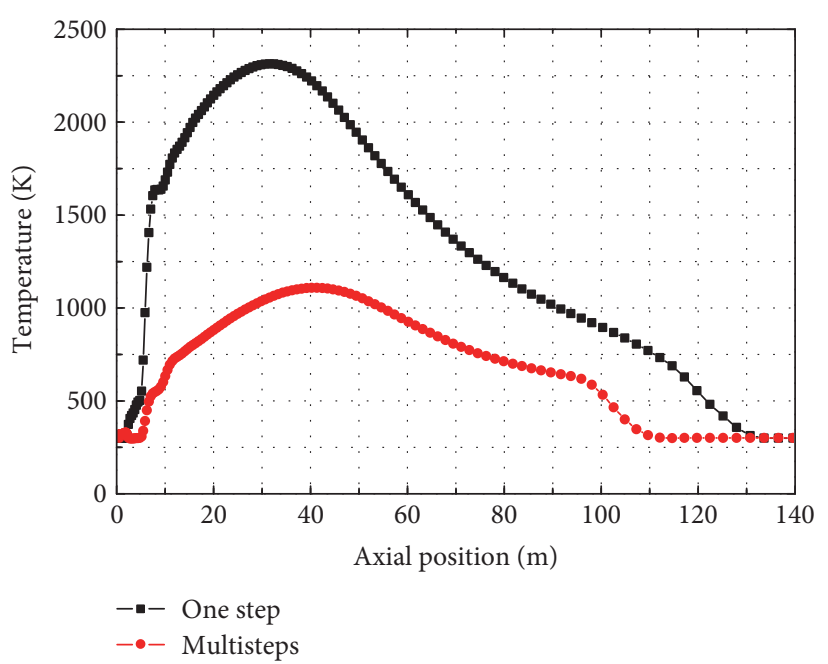

(a) Temperature

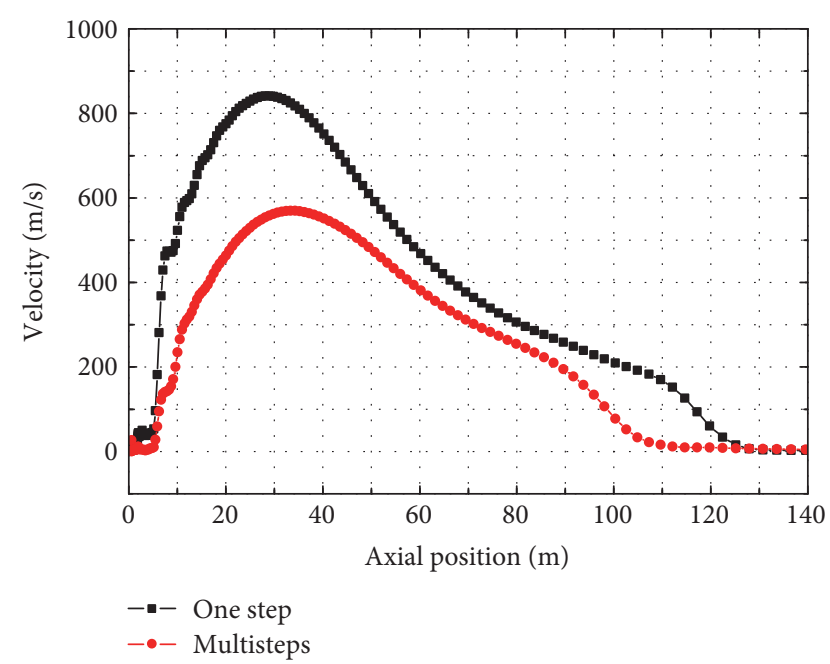

(b) Velocity

Figure 11: Parameters on the plume axis of the double-nozzle engine.

the afterburning reaction described by single-step global chemical reaction.

Different chemical reaction mechanisms are adopted to describe the combustion reaction to calculate the flow field of the double-nozzle engine exhaust plume flow field, and the distribution of parameters on the axis is shown in Figure 11; the length of exhaust plume obtained by single-step chemical reaction is longer than that obtained by multistep chemical reaction, and the peak temperature and the peak velocity are $1205.55 \mathrm{~K}$ (about $108.81 \%$ of the latter) and $271.76 \mathrm{~m} / \mathrm{s}$ (about $47.71 \%$ of the latter), respectively. In conclusion, when analyzing the doublenozzle plume flow field characteristics or the engine mounting structure on the rocket body, we must give full consideration to the important influence of the chemical reaction model.

\section{Conclusion}

In this paper, a computational method of LOX/kerosene engine plume flow field is proposed. First, the internal combustion flow field of the engine is calculated, and the parameters of the nozzle throat are obtained as the inlet boundary of plume flow field simulation. Then, the plume flow field is simulated. The method can fully consider the influence of the internal combustion state on the plume flow field and avoid the repeated calculation of the internal flow field of the engine when calculating the exhaust plume of a multinozzle engine. The effects of different chemical reaction mechanisms on the single-nozzle and the double-nozzle LOX/kerosene engine exhaust plumes are analyzed based on the method. The conclusions are as follows:

(1) Multistep chemical reaction can be more accurate compared with one-step chemical reaction on the description of LOX/kerosene engine internal combustion process.
(2) The plume structures of the single-nozzle and the double-nozzle LOX/kerosene engine exhaust plumes with different chemical reaction mechanisms are similar, but the length of plume flow field based on the single-step chemical reaction is longer, the temperature is higher, and the speed is faster.

(3) Double-nozzle engine plume flow field is formed by two sets of single-nozzle plume flow field. Due to the temperature and velocity, distributions of single-nozzle engine plume flow field based on multistep and one-step chemical reaction are completely different and the double-nozzle engine plume flow field based on multistep and one-step chemical reaction is different. Analysis of double-nozzle plume flow field characteristics or the engine mounting structure on the rocket body and the influence of the chemical reaction mechanism must be fully considered.

\section{Conflicts of Interest}

The authors declare that they have no conflicts of interest.

\section{References}

[1] G. Terry, S. David, and P. Robert, "Analysis of liquid rocket propellant engine exhaust plumes," in AIAA 5th Thermophysics conference, Los Angeles, CA, USA, June 29-July 1, 1970.

[2] D. R. Gonzalez, P. Walman, M. Sanford, J. Monat, and J. Carney, "Characterization of rocket-plume fluid-dynamic environment using numerical and experimental approaches," Journal of Spacecraft and Rockets, vol. 50, no. 3, pp. 527-539, 2013.

[3] G. P. Sutton and O. Biblarz, Rocket propulsion elements, John Wiley \& Sons, New York, NY, USA, 7th edition, 2001.

[4] F. S. Simmons, Rocket Exhaust Plume Phenomenology, The Aerospace Press, AIAA, Reston, VA, USA, 1st edition, 2000. 
[5] A. Mathur, "Rocket plume attenuation model," in 24th AIAA International Communications Satellite Conference, San Diego, CA, USA, June 2006.

[6] H. William and J. Calhoon, "Computational assessment of afterburning cessation mechanisms in fuel-rich rocket exhaust plumes," Journal of Propulsion and Power, vol. 17, no. 1, pp. 111-119, 2001.

[7] G. Marshall, H. Jeffrey, and K. Cetin, "Best practices for CFD simulations of launch vehicle ascent with plumes - OVERFLOW perspective," in 49th AIAA Aerospace Science Meeting including the New Horizons Forum and Aerospace Exposition, Orlando, FL, USA, January 2011.

[8] S.-c. Hu, F.-t. Bao, Z. Wang, and Q. Cai, "Numerical simulation of jet flow field and noise in nozzle," Journal of Solid Rocket Technology, vol. 34, no. 4, pp. 436-439, 2011.

[9] S.-c. Hu, F.-t. Bao, and Y. Zhao, "Numerical simulation for multi-jet aeroacoustics," Journal of Propulsion Technology, vol. 33, no. 3, pp. 430-435, 2012.

[10] X.-f. Xie, Z.-b. Ren, and X.-y. Cao, "Model building and analysis on infrared radiation characteristics of exhaust plume of cruise missils," Opto-Electronic Engineering, vol. 36, no. 4, pp. 70-74, 2009.

[11] H.-h. Cai, N. Wan-sheng, and Z. Gang, "Impact of the inner nozzle surface on plume characteristics of LOX/kerosene engine," Missile and Space Vehicles, vol. 5, pp. 35-38, 2015.

[12] S.-j. Feng, N. Wan-sheng, and X. Qing-fen, "Influence of combustion model in chamber on exhaust plume flow field and radiance," Journal of Rocket Propulsion, vol. 32, no. 2, pp. 6-10, 2006.

[13] T. S. Wang, R. C. Farmer, and R. B. Edelman, "Turbulent combustion kinetics for complex hydrocarbon fuels," in AIAA 26th Aerospace Sciences Meeting, Reno, USA, January 1988.

[14] R. B. Edelman and P. T. Harsha, "Laminar and turbulent gas dynamics in combustors current status," in 34th Fluid Mechanics \& Heat Transfer, Cleveland, OH, USA, March 1977.

[15] B. T. Vu, N. Bachchan, O. Peroomian, and V. Akdag, "Multiphase modeling of water injection on flame deflector," in 21st AIAA Computational Fluid Dynamics Conference, San Diego, CA, USA, June 2013.

[16] C. Hong-hua, N. Wan-sheng, and H. Zhi-yong, "Impact effect of liquid rocket motor exhaust plume on launching platform," Journal of Aerospace Power, vol. 31, no. 8, pp. 1995-2001, 2016.

[17] P. Pascal, F. Thomas, and V. Hilda, "Lox/methane and Lox/ kerosene high thrust engine trade-off," in 37th AIAA/ ASME/SAE/ASEE Joint Propulsion, Salt Lake City, UT, USA, July 2001. 


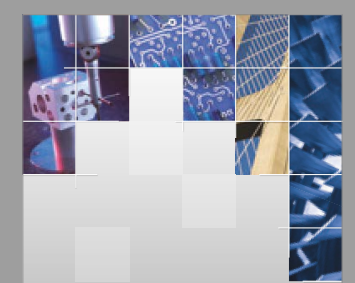

\section{Enfincering}
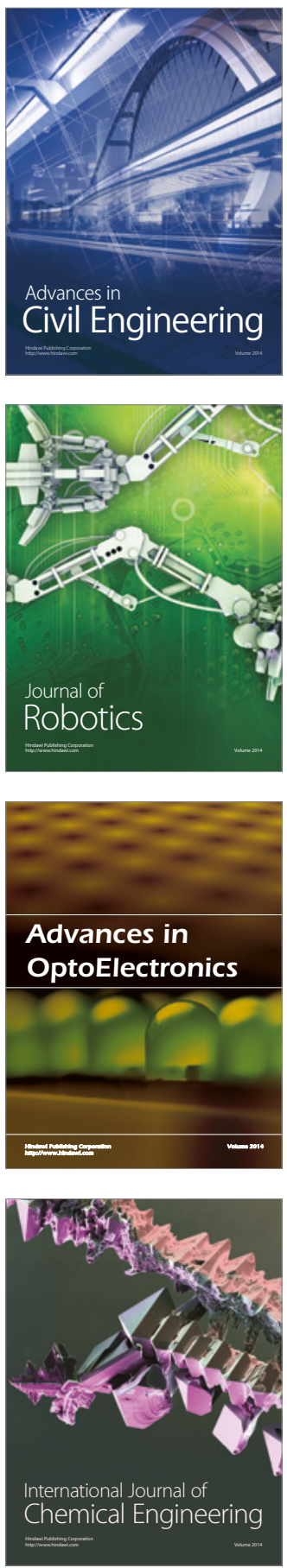

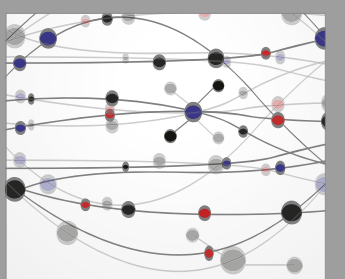

The Scientific World Journal

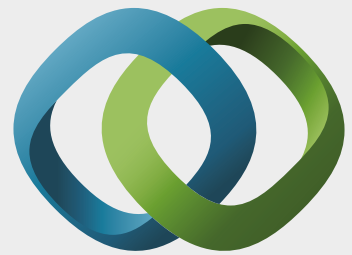

\section{Hindawi}

Submit your manuscripts at

https://www.hindawi.com
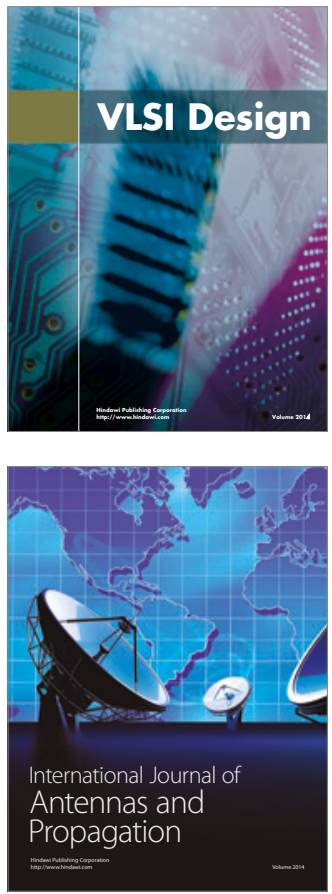

\section{Rotating}

Machinery
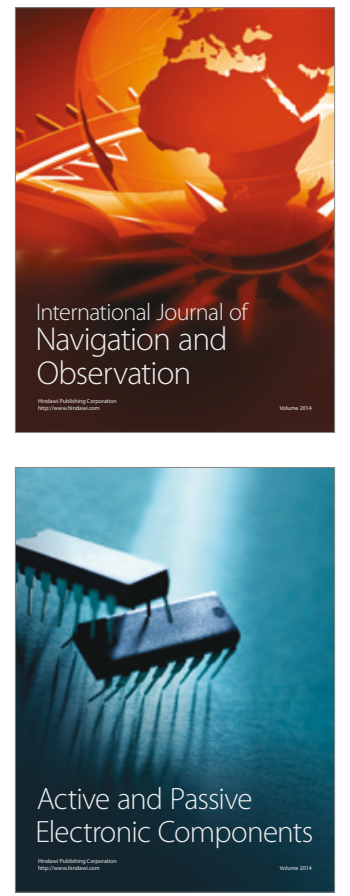
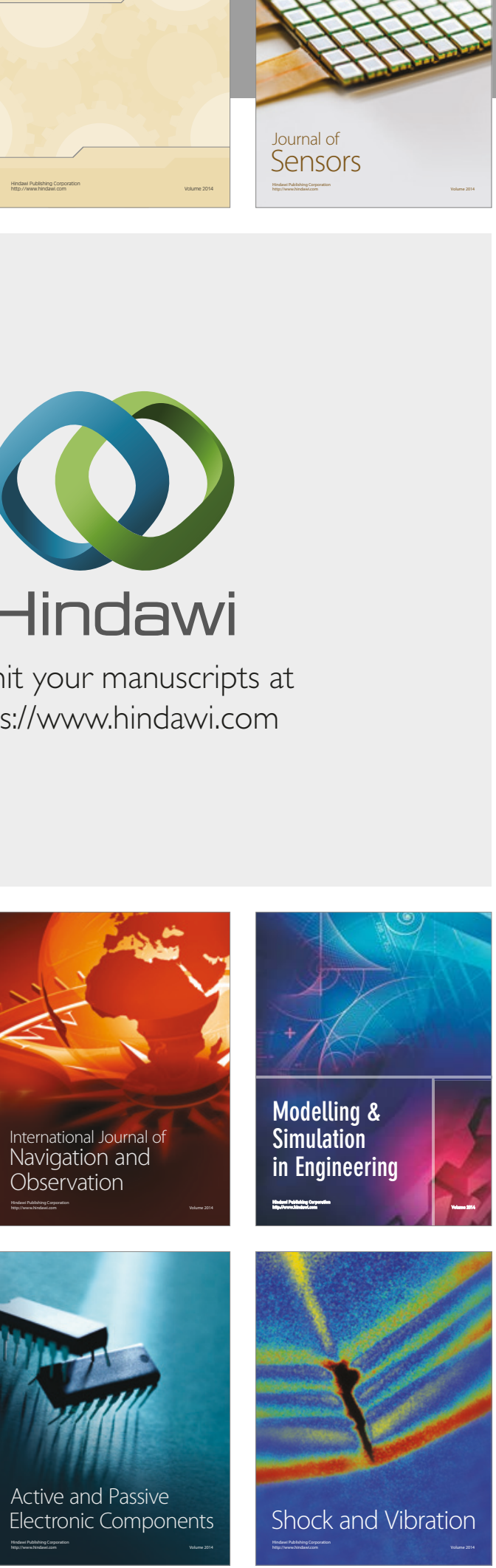
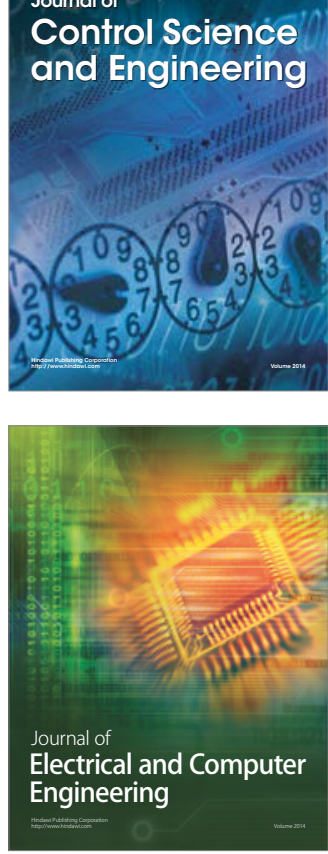

Distributed

Journal of

Control Science

and Engineering
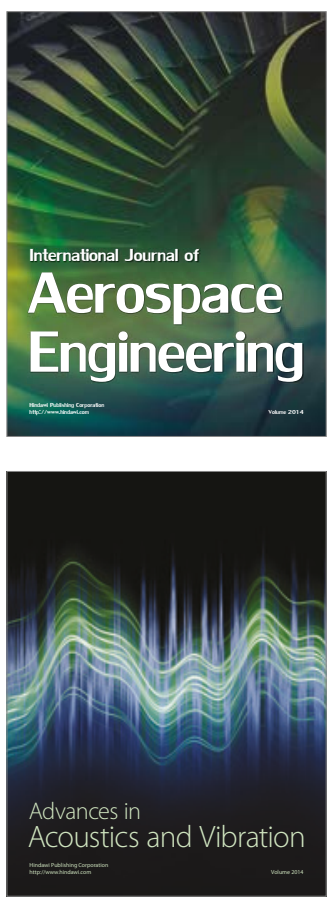

Sensor Networks 